\title{
THE PHASE DIAGRAM FOR THE BINARY SYSTEM INDIUM-TELLURIUM AND ELECTRICAL PROPERTIES $\mathrm{OF} \quad \mathrm{In}_{3} \mathrm{Te}_{5} *$
}

\author{
EDWARD G. GROCHOWSKI, $\dagger$ DONALD R. MASON, GERALD A. SCHMITT \\ and PHILLIP H. SMITH $\ddagger$
}

The Department of Chemical and Metallurgical Engineering. The University of Michigan Ann Arbor, Michigan

(Received 22 October 1963; revised 13 December 1963)

\begin{abstract}
The phase diagram for the binary system indium-tellurium has been clarified and corrected, particularly in the region near the composition $\mathrm{In}_{2} \mathrm{Te}_{3}$. This material is a potentially important semiconductor, either alone or in combination with other materials, such as $\mathrm{Cu}_{3} \mathrm{Te}$, $\mathrm{Ag}_{2} \mathrm{Te}, \mathrm{CdTe}$, etc.

Results of this study were obtained by correlating differential thermal analysis (DTA), chemical analyses of zone-refined ingots, microscopic analysis, and X-ray determinations.

Two new phases have been identified, and the compositions of three other phases have been determined more precisely.

(1) The phase $\mathrm{In}_{2} \mathrm{Te}\left(33 \cdot 3\right.$ at. $\% \mathrm{Te}$ ) does not exist; the composition should be $\operatorname{In}_{9} \mathrm{Te}_{7}(43$ at. \% Te). The peritectic decomposition temperature is $462^{\circ} \mathrm{C}$.

(2) The phase InTe $\left(50.0\right.$ at. \% Te) has the composition $\operatorname{In}_{30} \mathrm{Te}_{31}(50.8$ at. \% Te). The congruent melting point is $696^{\circ} \mathrm{C}$.

(3) A new phase $\mathrm{In}_{3} \mathrm{Te}_{4}(57.0$ at. $\% \mathrm{Te}$ ) has been found having a peritectic decomposition temperature of $650^{\circ} \mathrm{C}$.

(4) The phase $\operatorname{In}_{2} \mathrm{Te}_{3}(60.0$ at. $\% \mathrm{Te})$ has the composition $\mathrm{In}_{27} \mathrm{Te}_{40}(59.7$ at. $\% \mathrm{Te})$. The congruent melting point is $667^{\circ} \mathrm{C}$, and there is a phase transition at about $550^{\circ} \mathrm{C}$.

(5) A new phase $\operatorname{In}_{3} \mathrm{Te}_{5}(62.5$ at. $\% \mathrm{Te})$ has been found, having a peritectic decomposition temperature of $625^{\circ} \mathrm{C}$, and a phase transition at $463^{\circ} \mathrm{C}$.

(6) The phase $\operatorname{In}_{2} \mathrm{Te}_{5}(71 \cdot 5$ at. $\% \mathrm{Te})$ was prepared.

(7) Electrical measurements on $\mathrm{In}_{3} \mathrm{Te}_{5}$ show a large conductivity increase associated with the phase transition at $463^{\circ} \mathrm{C}$.
\end{abstract}

(8) Electrical measurements on zone refined $\operatorname{In}_{2} \mathrm{Te}$, were non-reproducible.

\section{INTRODUCTION}

Because of the potential importance of compounds in a binary system indium-tellurium ${ }^{(1,2)}$ as semiconductor materials, a re-investigation of this phase diagram has been undertaken to clarify and correct certain discrepancies in the published literature. This report is an extension of comments

* Contribution No. 7 from The Semiconductor Materials Research Laboratory, The College of Engineering, The University of Michigan, Ann Arbor, Michigan.

$\dagger$ Present address: International Business Machines Corporation, Semiconductor Division, Poughkeepsie, New York.

$\mp$ Present address: Chevrolet Engineering Center, Warren, Mich. which were made in Prague in discussing a paper

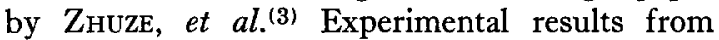
differential thermal analysis data, microscopic analyses, electrical measurements and chemical analyses of zone-refined ingots have been correlated with data from the literature in arriving at the phase diagram presented in this paper.

\section{EXPERIMENTAL PROCEDURES}

All the samples were prepared by pyrosynthesis from pure elements, ${ }^{(4)}$ and the differential thermal analyses (DTA) were carried out on powdered samples sealed under vacuum in clear quartz tubes with an axial thermocouple well. The methods used have been previously described in more 
552 EDWARD G. GROCHOWSKI, DONALD R. MASON, GERALD A. SCHMITT and PHILLIP H. SMITH

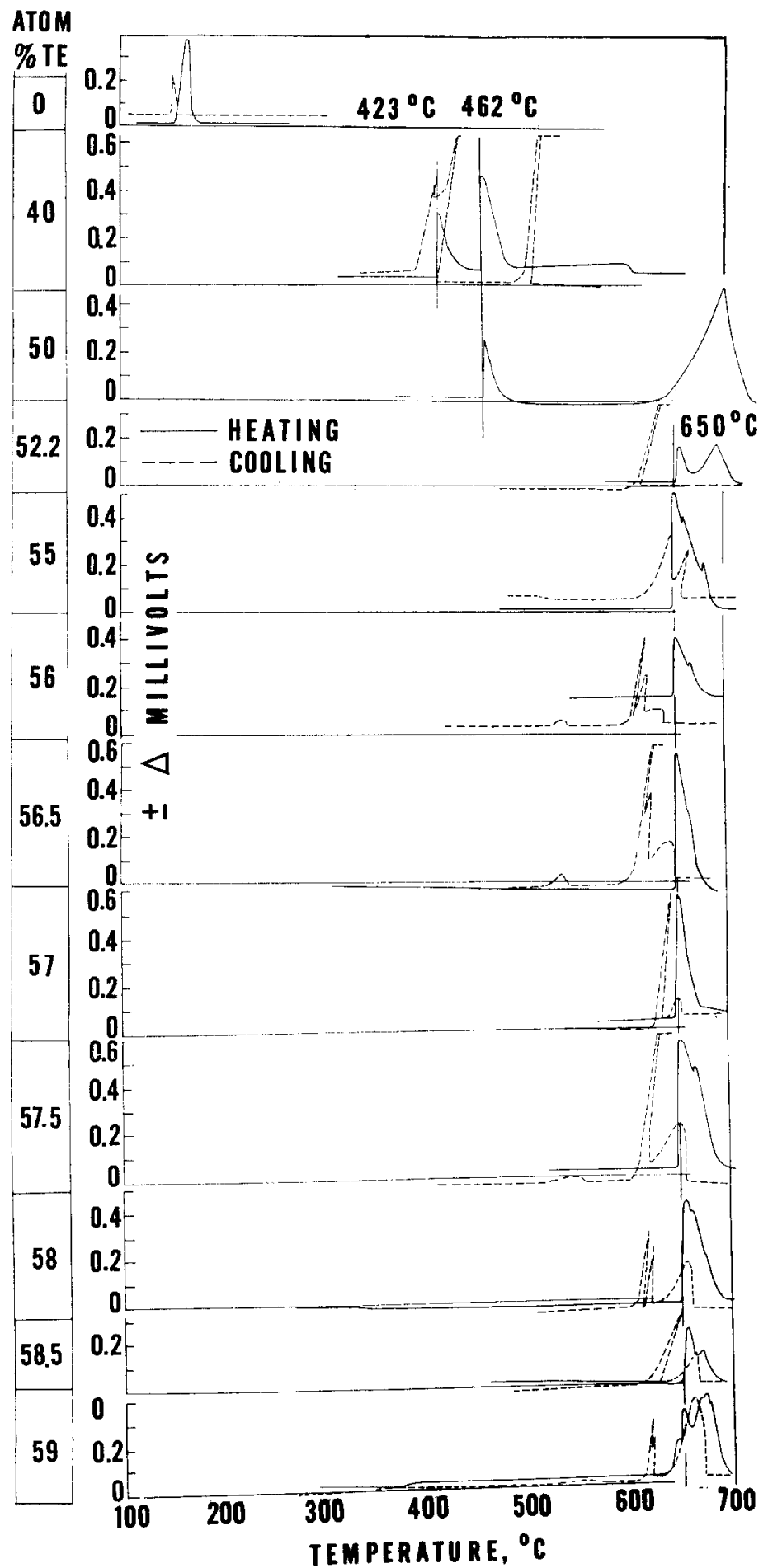

(a) 


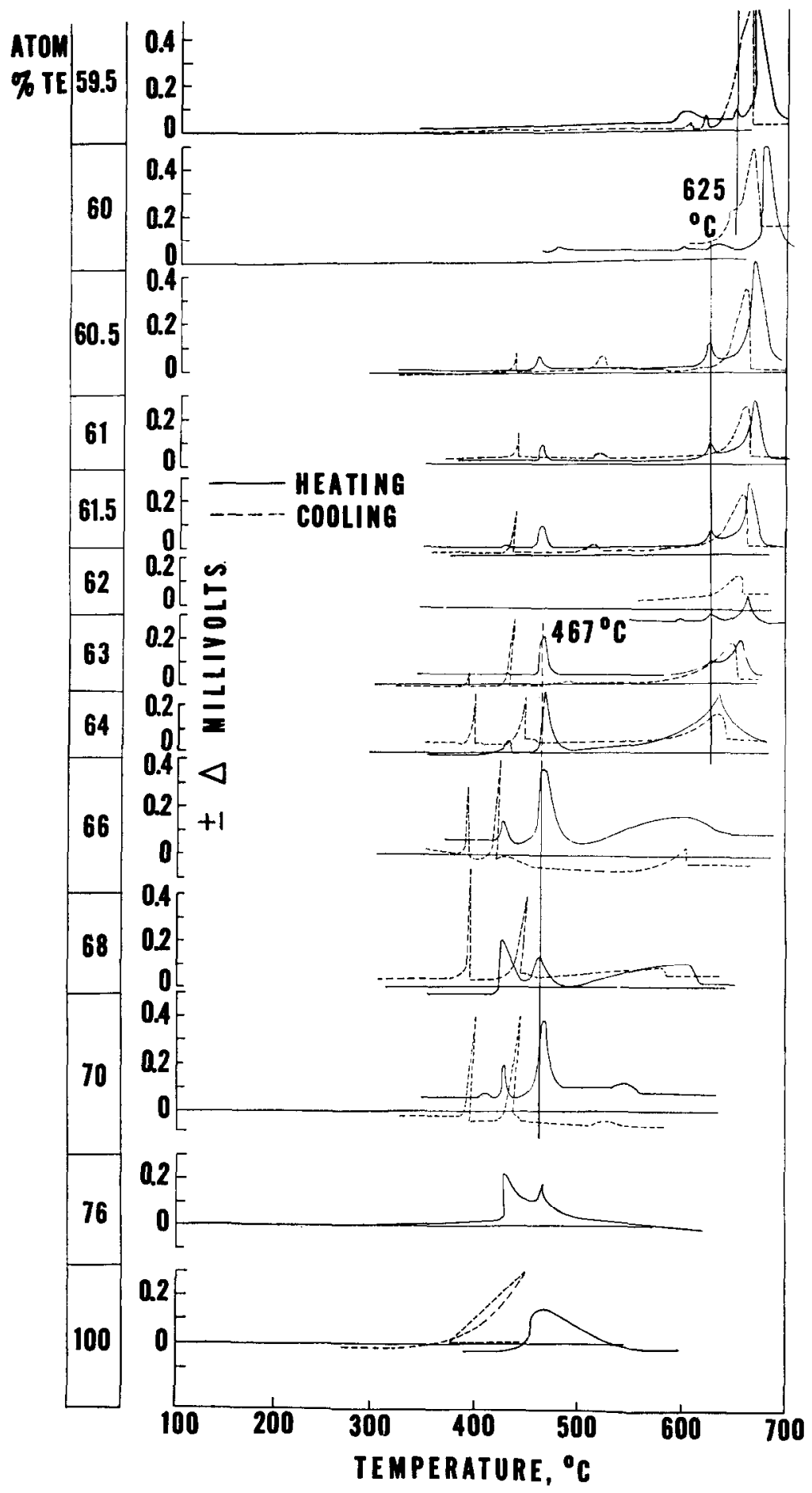

(b)

FIG. 1. Differential thermal analysis curves for the indium-tellurium system. (a) 0-59 at.\% Te; (b) 59.5-100 at.\% Te. The solid lines are the heating cycle and the broken lines are the cooling cycle. 
detail. ${ }^{(5,6)}$ Most of the samples were measured using a Leeds and Northrup Model G Speedo$\max x-y$ Recorder to plot differential e.m.f. vs. sample temperature directly. Liquid indium was used as a reference and the samples were heated and cooled at a rate of about $2 \cdot 5^{\circ} \mathrm{C} /$ min.

Conventional, unidirectional zone refining was used to prepare pure samples of the congruently melting compounds, InTe and $\mathrm{In}_{2} \mathrm{Te}_{3}$, starting with compositions on either side of the congruently melting compositions. The solid portions of the ingot were held above $350^{\circ} \mathrm{C}$ during zone refining to prevent condensation of the Te vapor arising from the molten zone. Large $70 \mathrm{~g}$ peritectic samples about $10 \mathrm{in.}$ long were zone leveled by the technique devised by MAson and $\operatorname{Cook}^{(7)}$ to provide sufficient material for further analyses. Zone lengths were maintained at $1 \frac{1}{4}$ in. in length and the number of passes was normally from 8 to 10 for each ingot.

When single phase regions of peritectic compounds were obtained, as determined by microscopic examination, they were analysed chemically. The analytical results then were used to determine the composition of the next sample for the zone refiner. When no single phase region was observed, a comparison between two such ingots indicated a variation of the amount of second phase as a function of composition. The composition of the ingots for zone-refining then was adjusted to eliminate the second phase.

The exact composition for each compound of the phase diagram was determined by chemical analysis of zone-refined ingots. A simple analytical technique was developed in which the samples were dissolved in aqua regia, the excess nitric acid was boiled off, and the tellurium ions were reduced by sulfur dioxide. The elemental tellurium precipitate was dried in a moderate vacuum at $60^{\circ} \mathrm{C}$ to minimize oxidation. The method was reproducible to within $0 \cdot 1$ per cent, using $2 \mathrm{~g}$ analytical samples.

Several X-ray powder pattern photographs were taken using a $114.6 \mathrm{~mm}$ camera and $\mathrm{Cu}-\mathrm{K}_{\alpha}$ radiation through a nickel filter to eliminate the $\mathrm{Cu}-\mathrm{K}_{\beta}$ radiation. The $\mathrm{X}$-ray film was covered with aluminum foil to reduce spurious radiation effects. Either silicon or germanium was added to each sample to give reference lines on each film.

Electrical conductivity and Hall effect measure- ments were made on zone-refined, polycrystalline rectangular bars of $\mathrm{In}_{2} \mathrm{Te}_{3}$ and $\mathrm{In}_{3} \mathrm{Te}_{5}$. Measurements were made from room temperature to the melting points in nitrogen or hydrogen. Electrical contacts were made by fusing hot platinum wires onto the samples. The measurements were carried out using conventional d.c. techniques described by LINDERG ${ }^{\left({ }^{8}\right)}$ using a $2100 \mathrm{G}$ permanent magnet having a $2 \frac{1}{2}$ in. pole face and a $2 \frac{3}{4}$ in. gap. The sample holder was made from fired lava (lavite) and has been described in more detail by O'KANE. ${ }^{(9)}$

\section{EXPERIMENTAL RESULTS}

The results from most of the 36 D'TA runs are plotted in Fig. 1, showing differential thermocouple e.m.f. for chromel-alumel thermocouples as a function of sample temperature and sample composition. The significant, reproducible eutectic temperature at $650^{\circ} \mathrm{C}$ is indicated, along with the peritectic temperatures at 462,467 and $625^{\circ} \mathrm{C}$. The monotectic at $423^{\circ} \mathrm{C}$ is also shown. More than 35 zone refining samples were prepared and analysed in these tests.

The results of this work are summarized in the phase diagram shown in Fig. 2, which is a drastic revision of the phase diagram published by HANSEN. (2) In going across the diagram the pertinent features are as follows:

(1) As Te is added to the pure In ( $\alpha$-phase) a peritectic at $160^{\circ} \mathrm{C}$ is formed instead of a eutectic.

(2) The monotectic in the high indium end of the diagram is confirmed by the transition at $423^{\circ} \mathrm{C}$.

(3) We find no evidence for the existence of In 2 Te. Instead, we believe that the peritectic occurs at about $462^{\circ} \mathrm{C}$ and 43 at. $\%$ Te, ${ }^{*}$ and is $\mathrm{In}_{9} \mathrm{Te}_{7}$. This has been substantiated by DTA results and peritectic zone refining experiments.

(4) This work confirms the existence of the congruent compound InTe with a melting point of $696^{\circ} \mathrm{C}$, as shown, although its composition actually is at 50.8 at. $\% \mathrm{Te},{ }^{*}$ and therefore can be reported more precisely as $\operatorname{In}_{30} \mathrm{Te}_{31}$.

(5) The first new compound in this system is $\mathrm{In}_{3} \mathrm{Te}_{4}$ which decomposes peritectically at about

* All compositions are reported as atom \% $\%$ Te, based on mol. wt $\mathrm{Te}=127 \cdot 61$, mol. wt Indium $=114 \cdot 82$; IUPAC, 1957. 


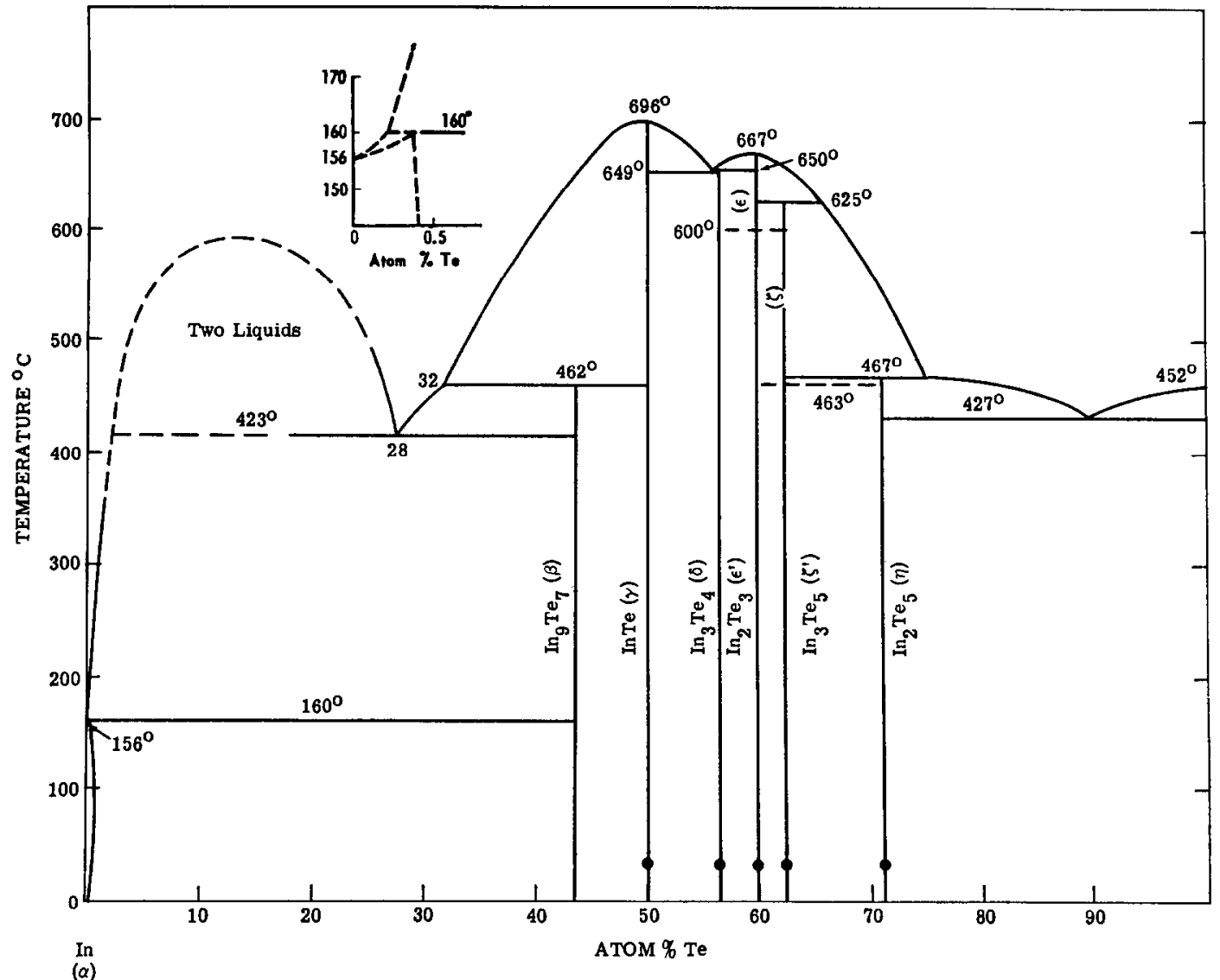

Fig. 2. Phase diagram for the indium-tellurium system.

$650^{\circ} \mathrm{C}$. This is so close to the $649^{\circ} \mathrm{C}$ eutectic between InTe and $\mathrm{In}_{3} \mathrm{Te}_{3}$ that it was overlooked at first. However, on the DTA cooling curves shown in Fig. 1 two supercooled transitions are observed between 56 and $59 \%$ Te, which are characteristic of a peritectic-eutectic system. Samples from ingots which were zone refined in the normal manner starting at $58 \%$ Te showed an almost homogeneous phase in the center region with composition of about $57.5 \%$ Te. From chemical analysis, it was found that the high melting end had a composition of $59.7 \% \mathrm{Te}$, and the eutectic had a composition of $56.2 \%$ Te. Analysis of X-ray powder patterns on a sample at $56 \% \mathrm{Te}$ showed some lines characteristic of InTe, but there were in addition a large number of lines which were not characteristic of $\mathrm{In}_{2} \mathrm{Te}_{3}$ patterns taken on either "ordered" samples or "disordered" samples.
Additional X-ray measurements made on a sample at $57.5 \% \mathrm{Te}$ showed 59 lines, 12 of which are common to InTe, and 3 of which are common to $\mathrm{In}_{2} \mathrm{I}^{\prime} \mathrm{e}_{3}$. However, 44 of the lines belong to neither phase, thus confirming the existence of this new compound. Holmes et al. ${ }^{(10)}$ seem to have missed this compound in their investigations.

(6) The compound $\mathrm{In}_{2} \mathrm{Te}_{3}$ also exists and melts at $667^{\circ} \mathrm{C}$, although its composition is actually at 59.7 at. \% Te, and therefore can be reported more precisely at $\mathrm{In}_{27} \mathrm{Te}_{40}$. The transformation of $\mathrm{In}_{2} \mathrm{Te}_{3}$ from a disordered structure to an ordered structure has been reported by many workers, including Woolley et al., (11) ZaslavsiII and Sergeyeva, (12) and GASSON et al. ${ }^{(13)}$ ZHUZE et al. ${ }^{(14)}$ report an order-disorder transformation in $\mathrm{In}_{2} \mathrm{Te}_{3}$ at $550^{\circ} \mathrm{C}$. From our work the transformation appears to occur between 550 and $600^{\circ} \mathrm{C}$. 
(7) The presence of the second new compound, $\mathrm{In}_{3} \mathrm{Te}_{5}$ was indicated by DTA measurements. Samples were prepared by zone leveling techniques, and characterized by chemical, electrical and X-ray analyses. Our X-ray analysis suggests that it has most of the same diffraction lines that have been reported by WOOLLEY et al. ${ }^{(11)}$ and by ZaSLAVSIII and SERgEYEVA (12) for "ordered" In 2 'Te 3 . There is a solid-solid transformation in this material which occurs somewhere between 440 and $465^{\circ} \mathrm{C}$. Until confirmed by electrical measurements, the DTA results of this transformation were at first interpreted as an extension of the $\mathrm{In}_{2} \mathrm{Te}_{5}$ peritectic transformation in non-homogeneous DTA samples. It is now apparent that the DTA transitions between 60 and $63 \% \mathrm{Te}$ have an average temperature of $463^{\circ} \mathrm{C}$, whereas those observed between 64 and $70 \%$ Te have an average temperature of $467^{\circ} \mathrm{C}$.

(8) The compound $\mathrm{In}_{2} \mathrm{Te}_{5}$ also seems to be confirmed, although its peritectic transformation temperature is at $467^{\circ} \mathrm{C}$.

\section{ELECTRICAL PROPERTIES AND STRUCTURE OF $\operatorname{In}_{3} \mathrm{Te}_{5}$}

Some electrical conductivity and Hall effect measurements have been made on $\mathrm{In}_{3} \mathrm{Te}_{5}$. Measurements were made in nitrogen or hydrogen. ZHUZE et al. ${ }^{(14)}$ report that erroneous results are noted when measurements were made in any atmosphere which might contain traces of oxygen. This was attributed to surface oxidation. Hence, hydrogen has been used in all our recent measurements but there has been no detectable change from our earlier measurements. Below about $460^{\circ} \mathrm{C}$ the measurements are not always reproducible, as shown in Fig. 3. At $460^{\circ} \mathrm{C}$ there is an abrupt increase in the conductivity by a factor of about 30 . The data extend up to about $500^{\circ} \mathrm{C}$ and suggest an apparent energy gap of about $1.06 \mathrm{eV}$.

Since the first sample of $\mathrm{In}_{3} \mathrm{Te}_{5}$ appeared to be non-homogeneous, a section of the ingot was annealed for 7 days in vacuum at $425^{\circ} \mathrm{C}$ before bcing mcasurcd. Bclow the transition temperature the results were quite different from those measured on the first sample, and the transition temperature has been decreased by $15^{\circ} \mathrm{C}$ to $445^{\circ} \mathrm{C}$. Above this transition, the measurements are poor but suggest a gap of $0.99 \mathrm{eV}$, which is acceptably close to the value $1.06 \mathrm{eV}$ measured on the unannealed sample. Inspection of the samples after measurement showed no evidence that the sample had partially melted or otherwise entered a liquid-containing region of the phase diagram.

The transition in the electrical properties of $\mathrm{In}_{2} \mathrm{Te}_{3}$ at about $470^{\circ} \mathrm{C}$ observed by WoOLLEY and PAMPLIN ${ }^{(15)}$ probably arises from contamination of this sample by $\operatorname{In}_{3} \mathrm{Te}_{5}$. This seems particularly true since this effect has not been observed by ZHUZE et al., (14) by APPEL, (16) or by us.

An X-ray structure determination on the high temperature form of $\operatorname{In}_{3} \mathrm{Te}_{5}$ indicates that it has a hexagonal structure, with $c=3.56 \AA, a=13.27 \AA$, and $c / a=0.27$. If all the $\mathrm{Te}^{-2}$ atoms in a close-packed array, then there should be $16 \mathrm{Te}^{-2}$ atoms per unit cell, or 3.20 molecules of $\mathrm{In}_{\mathbf{3}} \mathrm{Te}_{5}$ with a theoretical density $\rho=5.68 \mathrm{~g} / \mathrm{cm}^{3}$. A pycnometer density measurement on this material gave a density, $\rho=5.87 \mathrm{~g} / \mathrm{cm}^{3}$, which clearly indicates that some of the Te atoms are on cation sites. The semiconducting properties of $\mathrm{In}_{3} \mathrm{Te}_{5}$ can be explained on the basis of the MooserPEARSON rules ${ }^{(17)}$ by assuming that the formula is actually $\mathrm{In}_{18}^{+3} \mathrm{Te}^{+4} \mathrm{Te}_{29}^{-2}$. Hence, in each unit cell there are actually $16.55 \mathrm{Te}$ aloms or 3.31 molecules of $\mathrm{In}_{3} \mathrm{Te}_{5}$. This compound is in conformity with the Mooser-Pearson formula

$$
\frac{n_{e}}{n_{A}}+b_{A}-b_{c}=8,
$$

where

$$
\begin{gathered}
n_{e}=3 \times 3+5 \times 6=39=\text { number of electrons } \\
\text { in valence orbitals/formula wt. } \\
n_{A}=5=\text { number of group IVb to VIIb } \\
\text { (anion) atoms/formula wt. } \\
b_{A}=6 / 30=0 \cdot 2=\text { average number of anion- } \\
\text { anion bonds/anion. } \\
b_{c}=0 \begin{array}{c}
\text { = average number of cation-cation } \\
\text { bonds/cation. }
\end{array}
\end{gathered}
$$

The equality is valid since one $\mathrm{Te}$ atom in 30 goes into a cation site and makes six bonds to neighboring Te atoms in anion sites.

\section{ELECTRICAL MEASUREMENTS ON $\operatorname{In}_{2} \mathrm{Te}_{3}$}

Electrical measurements have been made on a sample of $\operatorname{In}_{27} \mathrm{Te}_{40}\left(\operatorname{In}_{2} \mathrm{Te}_{3}\right)$ which was prepared by zone refining of a sample composition $\operatorname{In}_{40.8} \mathrm{Te}_{59.2}$. This sample then is indium-rich, whereas all previously reported measurements on 


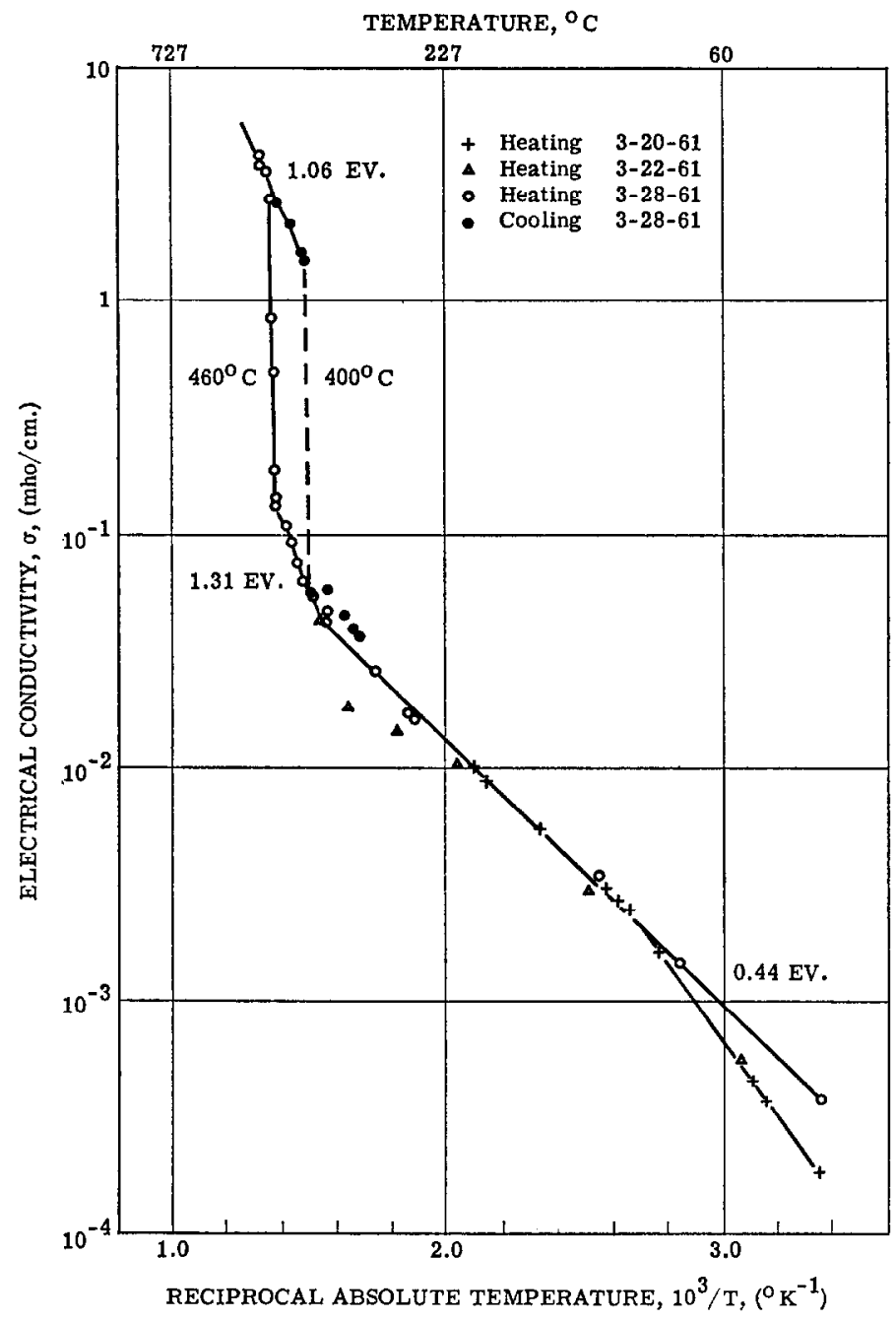

FIG. 3. Electrical conductivity of $\operatorname{In}_{3} \mathrm{Te}_{5}$ vs. reciprocal absolute temperature.

$\mathrm{In}_{2} \mathrm{Te}_{3}$ were apparently made on tellurium-rich samples. (14-16)

On the first measurement this sample had an apparent energy gap of $2 \cdot 2 \mathrm{eV}$ from 200 to $500^{\circ} \mathrm{C}$. At $500^{\circ} \mathrm{C}$, the sample underwent a transition and above about $550^{\circ} \mathrm{C}$ the energy gap appeared to be $3.6 \mathrm{eV}$. On cooling, the gap appeared to be equal to $1.1 \mathrm{eV}$. On reheating the $2.2 \mathrm{eV}$ gap did not appear but the sample retraced the $1.1 \mathrm{eV}$ curve. However, the transformation started at a lower temperature but eventually reproduced the $3.6 \mathrm{eV}$ curve after considerable instability over a $200^{\circ} \mathrm{C}$ temperature range (from 300 to $500^{\circ} \mathrm{C}$ ).

The electrical measurements on this compound are sufficiently variable and non-reproducible as to cast severe doubt on their validity, and more measurements are required before the characterization of $\mathrm{In}_{2} \mathrm{Te}_{3}$ is complete.

Acknowledgements-The authors would like to acknowlcdge assistance received from Prof. L. Thomassen, J. S. Cook, A. N. Currim, D. R. Johnson, B. M. 
Kulwicki, D. F. O'Kane, and G. D. Rose. This work was supported in part by Project MICHIGAN, under Department of the Army Contract (DA-36-039-SC78801) administered by the U.S. Army Corps, and in part by the Institute of Science and Technology at the University of Michigan.

\section{REFERENCES}

1. Klemm W. and Vogel H. U. v., Z. anorg. Chem. 219, 45-64 (1934).

2. HaNsen M., Constitution of Binary Alloys, pp. 863-4, 2nd Ed., McGraw-Hill, New York (1958).

3. Zhuze V. P., Zaslavskit A. E., Petrasevic V. M., Sergeyteva V. M., Smirnov I. E. and Selych A. I., Proceedings of the International Conference on Semiconductor Physics, pp. 871-881, Czechoslovak Academy of Sciences, Prague (1961).

4. HozaK N. L., Cook J. S. and Mason D. R., $J$. Electrochem. Soc. 108, 105-6 (1961).

6. Barnes C. E. and Mason D. R., Electrochem. Soc. Electron. Div. Abstr. 9, 8-11 (1960).

6. LaBotz R. J., Mason D. R. and O'Kane D. F., J. Electrachem. Soc. 110, 127 (1963).
7. Mason D. R. and CoOk J. S., J. Appl. Phys. 32, 475-477 (1961).

8. LindBerg O., Proc. Inst. Radio Engrs 40, 1414-1419 (1952).

9. O'Kane D. F., An Investigation of Ternary Semiconducting Compounds, Ph.D. Thesis, The University of Michigan, Ann Arbor (1962).

10. Holmes P. J., Jennings I. C. and Parrott J. E., J. Phys. Chem. Solids 23, 1-5 (1962).

11. Woolley J. C., Pamplin B. R. and Holmes P. J., J. Less-Common Metals 1, 362-376 (1959).

12. Zaslavski A. I. and Sergeyeva V. M., Solid-State Phys. (Russian) 2, 2872-2880 (1960).

13. Gasson D. B., Holmes P. J., Jennings I. C., Parrott J. E. and Penn A. W., Proceedings of the International Conference on Semiconductor Physics, pp. 1032-1038, Czechoslovak Academy of Sciences, Prague (1961).

14. Zhuze V. P., Sergeyeva V. M. and Shelykh A. E., Solid-State Phys. (Russian) 2, 2858-2871 (1960).

15. Woolley J. C., Pamplin B. R., J. Electrochem. Soc. 108, 874-879 (1961).

16. von APPel J., Z. Naturf. 9a, 265-267 (1953).

17. Mooser E. and Pearson W. B., in Progress in Semiconductors, Vol. 5, pp. 105-139 (edited by Gibson A. F.). Heyward, London (1960). 